\title{
Brucella melitensis endocarditis: successful treatment of an infected prosthetic mitral valve
}

\author{
J. B. O'MEARA, SUSANNAH EYKYN, B. S. JENKINS, \\ M. V. BRAIMBRIDGE and I. PHILLIPS \\ Departments of Cardiac Surgery, Microbiology, and Clinical Physiology, \\ St. Thomas' Hospital, London SE1
}

\begin{abstract}
O'Meara, J. B., Eykyn, Susannah, Jenkins, B. S., Braimbridge, M. V., and Phillips, I. (1974). Thorax, 29, 377-381. Brucella melitensis endocarditis: successful treatment of an infected prosthetic mitral valve. A 38-year-old man had a mitral valve replacement for rheumatic calcific mitral stenosis and regurgitation; following this operation he remained well for 10 months. He then presented with cough, abdominal pain, and rigors, and Brucella melitensis type 3 was repeatedly isolated from blood cultures. His clinical condition deteriorated rapidly and an emergency valve replacement was performed. $\mathrm{He}$ was then treated with co-trimoxazole for 12 months and made an excellent recovery. This is the first reported case of brucella endocarditis arising de novo on a prosthetic heart valve.
\end{abstract}

Endocarditis is a rare but serious complication of brucellosis. We report here a case of Brucella melitensis type 3 endocarditis occurring in a patient with a prosthetic mitral valve.

\section{CASE REPORT}

A 38-year-old Italian male restaurant proprietor underwent mitral valve replacement for rheumatic calcific mitral stenosis and regurgitation on 13 January 1972, with insertion of a No. 3 Starr Edwards mitral valve prosthesis type 6520 . On the fourth day after the operation he developed a pyrexia with a rigor. Blood cultures taken at this time were sterile but it was known that at least one bottle of intravenous fluid he had received was contaminated with Pseudomonas thomasii (Phillips, Eykyn, and Laker, 1972) and he was accordingly treated with a six-week course of co-trimoxazole to which the organism was known to be sensitive. Following this, the patient made a good recovery and remained well for 10 months, requiring only routine maintenance doses of digoxin and warfarin.

In November 1972, he developed a febrile illness with rigors and complained of cough and abdominal pain, and one week later he became progressively dyspnoeic on exertion and orthopnoeic. Blood was taken for culture and treatment was started with amoxycillin. However, his fever persisted and he developed left heart failure, requiring admission to St. Peter's Hospital, Chertsey on 21 November. Amoxycillin was discontinued and further blood cultures were taken. He was transferred to St. Thomas' Hospital on 25 November where more blood cultures were taken before treatment was begun with intravenous ampicillin and intramuscular streptomycin as it was considered that he had endocarditis. Two days later a slow-growing oxidase-positive Gram-negative bacillus was isolated from the blood cultures taken at Chertsey. It was strongly suspected that this organism might be Ps. thomasii and the antibiotic therapy was changed to intravenous cephalexin, trimethoprim, and sulphadiazine. However, the patient's condition deteriorated and cardiac catheterization with angiography was performed on 29 November. Right heart catheterization showed a right atrial mean pressure of $6 \mathrm{mmHg}$, pulmonary artery pressure of $40 / 28 \mathrm{mmHg}$, and pulmonary artery wedge pressure of $33 / 26 \mathrm{mmHg}$. Left heart catheterization showed an aortic pressure of $68 / 35 \mathrm{mmHg}$ and a left ventricular pressure of $75 / 7$ mmHg. Simultaneous pulmonary artery wedge end diastolic and left ventricular end diastolic pressures were 27 and $7 \mathrm{mmHg}$ respectively, indicating severe mitral stenosis. The cardiac output, as calculated by the Fick method, was $2 \cdot 7$ litres per minute and the calculated mitral valve area (Gorlin and Gorlin, 1951) was $0.55 \mathrm{~cm}^{2}$. The pulmonary vascular resistance was 1.48 units. Left ventricular cine-angiography showed a slightly dilated left ventricle which contracted reasonably well. Trivial mitral regurgitation was seen and an aortic root injection revealed a competent aortic valve.

In the light of these findings and the patient's clinical deterioration, an emergency operation for replacement of the prosthetic mitral valve was carried 
out later that day. A right anterolateral thoracotomy was performed and under cardiopulmonary bypass the mitral valve prosthesis was inspected and noted to be well healed on to the valve ring. However, thrombus was seen extending over the valve orifice from the margin of the prosthesis with the formation of a flap responsible for the functional stenosis (Figure). The prosthesis was excised and replaced with a No. 3 Starr Edwards mitral valve prosthesis type 6520.

At this time it was found that the organism, now growing in several of the blood cultures, was extremely sensitive to all antibiotics except clindamycin and could not possibly, therefore, be $P$ s. thomasii. It was then remembered that the patient's wife had apparently complained of rigors at the time of onset of her husband's illness and the possibility of brucellosis was considered. The organism was finally identified by Dr. D. J. H. Payne as Br. melitensis type 3. Serum taken from the patient before the emergency operation had a direct agglutination titre of $1: 2560$ to $\mathrm{Br}$. abortus and a Coombs titre of $1: 5120$ to Br. abortus. Complement fixation titres to both $\mathrm{Br}$. abortus and $\mathrm{Br}$. melitensis were $1: 256+$. Brucellae were eventually recovered from all the blood cultures taken from the patient at both hospitals and from the vegetations on the prosthetic valve.

Cephalexin was discontinued two days after the operation, and as soon as the patient could take oral therapy co-trimoxazole was given in place of intra- $\overrightarrow{\overrightarrow{\vec{S}}}$ venous trimethoprim and sulphadiazine. His immediate postoperative progress was complicated by $\frac{0}{0}$ pneumonia, presumed to be caused by Pseudomonas $\frac{\bar{D}}{\omega}$ aeruginosa that was repeatedly cultured from his bron- $\frac{\overrightarrow{ }}{\widehat{D}}$ chial aspirate. Tracheostomy was performed and $\varrho$ assisted ventilation was needed for nine days. The pneumonia gradually resolved after treatment with $\vec{\circ}$ gentamicin in addition to the co-trimoxazole. The? patient also developed a right hemiparesis with an $\vec{\omega}$ expressive dysphasia which had almost recovered $\omega_{\overparen{S}}$ when he was discharged from hospital to convales- $\vec{\sim}$ cence on 29 December. Co-trimoxazole was continued in a dose of two tablets three times a day until 2 Feb- 0 ruary 1973. It was then stopped for two weeks while $\omega$ further blood cultures were made; these were sterile. $y$ Therapy with co-trimoxazole was then restarted in a reduced dose of two tablets twice a day, and was con- $\frac{0}{\square}$ tinued until the end of November 1973 to complete 12 months' treatment. The patient has remained well.

\section{METHODS AND RESULTS}

ISOLATION OF ORGANISM FROM BLOOD CULTURE The : method used was that used routinely for all blood cultures in our laboratory. Venous blood, $10 \mathrm{ml}$, 方 was added to each of two bottles containing $10 \mathrm{ml}$ digest broth, $0.1 \%$ glucose, and $0.06 \%$ liquoid
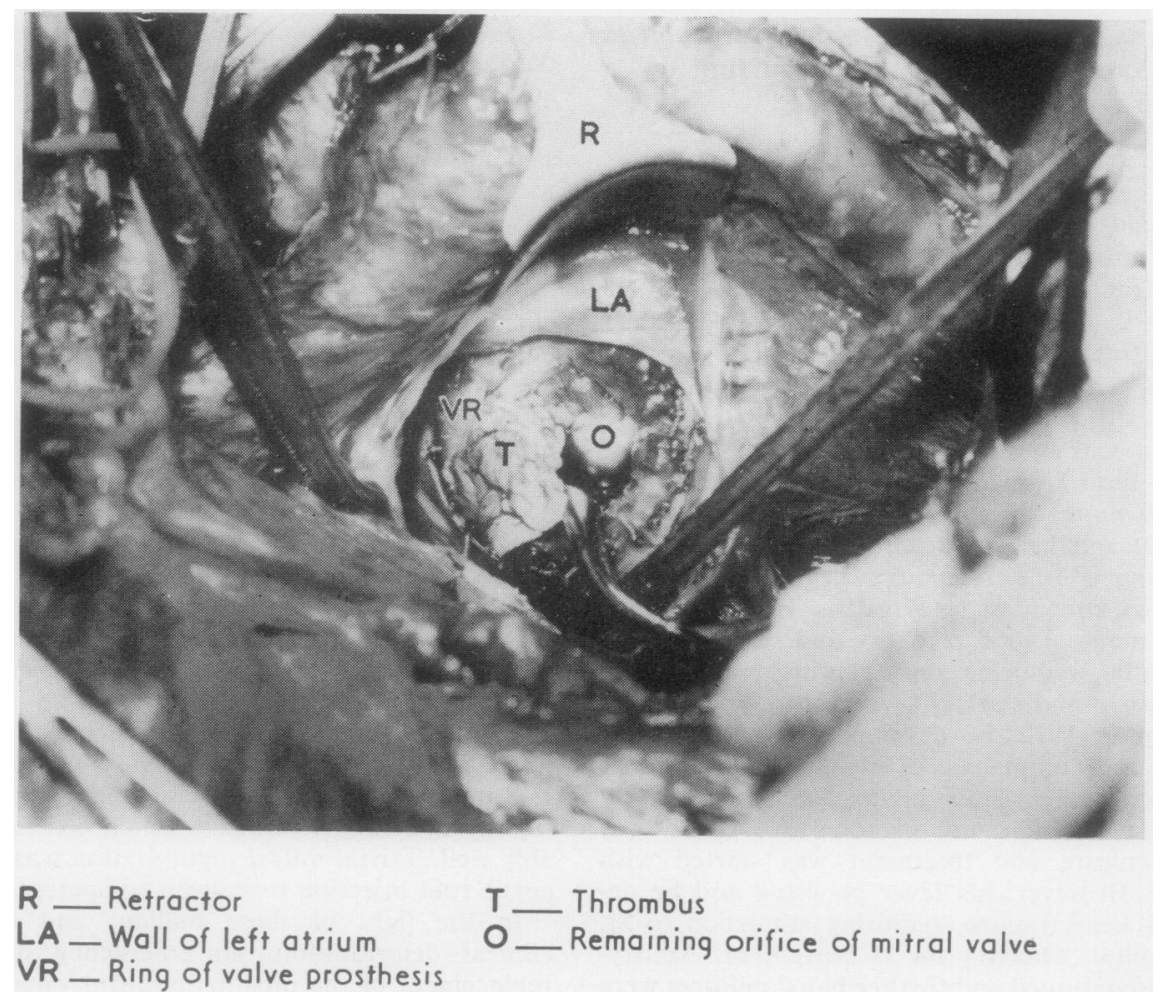
(Southern Group Laboratory). One culture was incubated in an atmosphere of carbon dioxide and the other contained a nail for anaerobic culture. Subcultures were made after 24 and 48 hours' incubation at $37^{\circ} \mathrm{C}$ on to blood agar. No growth was visible after 24 hours' incubation of the subculture, but after 48 hours tiny grey nonhaemolytic colonies were seen. These grew from anaerobic subcultures as well as those incubated in carbon dioxide.

ISOLATION OF ORGANISM FROM VEGETATIONS ON PROSTHETIC VALVE The vegetations were removed aseptically from the prosthetic valve. They were shaken for about 30 seconds in three successive $10 \mathrm{ml}$ aliquots of nutrient broth. A loopful of each of the broth washings was cultured. The vegetations were then crushed with a few drops of nutrient broth and a loopful of the crushed material was cultured. After 48 hours' incubation $\mathbf{B r}$. melitensis type 3 was isolated from the crushed vegetations but not from the broth washings.

ESTIMATION OF SERUM ANTIBODY TITRE The serum antibody titre was estimated by the direct agglutination test and the anti-human globulin (Coombs) test using the method described by Kerr et al. (1968). The antigen used was standardized Br. abortus agglutination concentrate obtained from the Central Veterinary Laboratory, Weybridge. A complement fixation test was also performed on the patient's serum by Dr. Payne.

EPIDEMIOLOGICAL INVESTIGATIONS The patient's family consisted of himself, his wife (Mrs. D) aged 35 , their son aged 14 , the patient's brother-in-law, his wife, and 2-year-old child. Only Mrs. D complained of any symptoms and $\mathrm{Br}$. melitensis type 3 was cultured from blood taken from her on 4 January 1973. No blood was cultured from the other members of the family. Serological investigations showed that Mrs. D's serum had a direct agglutination titre of $1: 1280$ to $B r$. abortus and a Coombs titre of $1: 640$ to $B r$. abortus. Insignificant titres were found in the other members of the family.

Although neither the patient nor his wife had visited their home in central Italy since his original operation, his brother-in-law brought over a large quantity of cheese from Italy in September 1972. The cheese was mostly Mozzarella but there was also some Pecorino. The cheeses were eaten by the patient, his wife, and son, and the patient admitted to having consumed large amounts of Mozzarella and some, but much less, Pecorino. Unfortunately, none of the cheeses remained for bacteriological investigation but the patient obtained a further supply of both cheeses from the same source. These were examined by Dr. Payne but no brucellae were recovered.

\section{DISCUSSION}

Brucellosis is a relatively common disease of man, particularly of farm workers and veterinarians. Approximately 600 cases of the disease are reported each year to the United Kingdom Public Health Laboratory Service (Henderson, 1973). The majority of these cases are diagnosed by serology and do not have positive blood cultures. Where brucellae are recovered from the blood they are nearly always $\mathrm{Br}$. abortus. Br. melitensis is rare in the United Kingdom but it is more readily isolated from the blood than $B r$. abortus. In the past 10 years, 24 cases of Br. melitensis infection with positive blood cultures have been reported to the Public Health Laboratory Service and only one of these was biotype 3 . In every case the infection was acquired abroad (Payne, 1973).

Endocarditis is a well recognized though rare complication of brucellosis and only four bacteriologically proven cases have been reported in the United Kingdom (Bassett-Smith, 1906; Rennie and Young, 1936; Hart, Morgan, and Lacey, 1951; Grant and Stote, 1953). The world-wide incidence of brucella endocarditis is much more difficult to assess as reports vary. Vogler, Dorney, and Bridges (1962) reported one case of Br. suis endocarditis in a review of 148 cases of endocarditis seen since 1948 in the Department of Medicine, Emory University Medical School, Atlanta. Jones (1950), in a review of world literature on bacterial endocarditis of non-streptococcal origin between 1936 and 1948, reported 15 cases due to brucellosis in a total of 212 patients. Giunchi, Pusic, and Tamburello (1951) found four cases of endocarditis in 150 patients with Malta fever, and Hardy (1943) reported a $1 \%$ incidence of endocarditis in patients with brucellosis. DalrympleChampneys (1950), on the other hand, reported no case of endocarditis in 978 cases of undulant fever though he refers to one case each of pericarditis and myocarditis.

The morbidity of human brucellosis is considerable but the mortality is very low. However, the most frequent cause of death in patients with the disease is congestive cardiac failure resulting from endocarditis. Peery and Belter (1960), in an exten- 
sive review of the world literature, found that in 44 cases of bacteriologically proven fatal brucellosis endocarditis was present at necropsy in 35 $(80 \%)$. It is interesting to note that brucella endocarditis appears to be exclusively a disease of males.

Fratini and Milli (1968) suggest that brucella endocarditis can be either primary, in which the infection occurs on a previously healthy valve, or secondary, in which it occurs on a valve that is abnormal, most commonly as a result of previous rheumatic fever. In the primary form the infection usually involves the aortic valve and in the secondary form the mitral valve is most commonly affected. Br. abortus in particular appears to have a specific though not exclusive affinity for the aortic valve.

Brucella endocarditis is therefore a rare disease, whether occurring on a previously healthy valve or on one already the seat of pathology. However, there is only one reported case in the world literature of brucella endocarditis involving a prosthetic valve. Ehrenhaft (1967) described a 23year-old male packing house worker who contracted brucellosis, for which he was treated, but who, two months later was found to have endocarditis with $\mathrm{Br}$. suis type 3 growing in the blood. Despite further treatment relapse occurred, and aortic valve replacement was undertaken for progressive cardiac failure from aortic regurgitation. The patient died 38 days after operation and at necropsy fresh vegetations were seen obstructing the prosthesis. $\mathrm{Br}$. suis type 3 was cultured from these vegetations. In this case the patient was already infected with brucellae before insertion of the prosthetic valve. The patient we have described was entirely well for ten months following the original mitral valve replacement and would seem to be the first case of brucella endocarditis arising de novo on a prosthetic heart valve. It is of particular interest that emergency valve replacement followed by a prolonged course of co-trimoxazole produced a successful outcome since the mortality of endocarditis of any aetiology on prosthetic valves is $72 \%$ (Shafer and Hall, 1970).

Although it was not conclusively proven that the cheese was the source of the brucella infecting this patient, this is extremely likely. It is known that $\mathrm{Br}$. melitensis infection is widespread in sheep in central Italy and cheese made from sheep's milk is recognized as an important source of human infection (Cariello and Tursi, 1964). Pecorino cheese is made from sheep's milk and this type of cheese was responsible for the outbreak of seven cases of $\mathrm{Br}$. melitensis type 2 infection in West Ham which was reported by Galbraith, Ross, de Mowbray, and Payne (1969). Authentic Italian Mozzarella is made from buffalo milk and comes from southern Italy but is widely distributed throughout the country (Marquis and Haskell, 1967). Brucellae can be transmitted through buffalo milk but there seems to be no information on how common brucellosis is in buffaloes. Soft Italian cheeses such as Mozzarella are usually salted to preserve them and $B r$. melitensis is known to survive for at least $\mathbf{1 0 0}$ days in $10 \%$ salt solution (Joint FAO/WHO Expert Committee on Brucellosis. Fifth Report, Geneva 1971).

The combination of tetracycline with streptomycin is generally accepted as the standard treatment for acute brucellosis. However, brucellae are highly sensitive to the combination of trimethoprim with sulphamethoxazole (co-trimoxazole) and this drug has been found to be very effective clinically in Br. melitensis infection provided treatment is continued for six weeks (Hassan et al., 1971). It was felt that in this patient prolonged antimicrobial therapy was indicated to protect the prosthetic valve which had been inserted in the presence of uncontrolled infection and that co-trimoxazole would therefore be easier to administer than the more traditional combination. This treatment seems to have been effective and has been completely free from side effects.

We thank Dr. D. J. H. Payne of the Public Health Laboratory, St. Mary's Hospital, Portsmouth for identification of the organism, for bacteriological investigation of the cheeses, and for his continuing interest and helpful advice. We also thank D. J. Mackinnon, B.Sc., M.R.C.V.S., of the FAO/WHO Brucellosis Centre, Weybridge, for performing the oxidative metabolic tests on the organism.

\section{REFERENCES}

Bassett-Smith, P. W. (1906). Some clinical features of Mediterranean fever; with particular reference to cardiac complications. British Medical Journal, 1, 313.

Cariello, M. and Tursi, L. (1964). Aspetti epidemiologici clinici e medico-sociali della brucellosi nel Molise. Annali della Sanita Pubblica, 25, 1041.

Dalrymple-Champneys, W. (1950). Undulant fevera neglected problem. Lancet, 1, 429.

Ehrenhaft, J. L. (1967). In discussion of a paper by Kaiser, G. C., Willman, V. L., Thurmann, M., and Hanlon, C. R. (1967). Valve replacement in cases of aortic insufficiency due to active endocarditis. Journal of Thoracic and Cardiovascular Surgery, 54, 491. 
Fratini, M. and Milli, G. C. (1968). Due casi di endocardite in corso di grave sepsi brucellare. Giornale di Malattie Infettive de Parassitarie, 20, 373.

Galbraith, N. S., Ross, M. S., de Mowbray, R. R. and Payne, D. J. H. (1969). Outbreak of Brucella melitensis type 2 infection in London. British Medical Journal, 1, 612.

Giunchi, G., Pusic, G., and Tamburello, S. M. (1951). Endocardite brucellare. Cuore e Circolazione, 35, 129.

Gorlin, R. and Gorlin, S. G. (1951). Hydraulic formula for calculation of the area of the stenotic mitral valve, other cardiac valves, and central circulatory shunts. American Heart Journal, 41, 1.

Grant, G. H. and Stote, C. L. (1953). Rupture of the heart as a result of $B r$. abortus endocarditis. British Medical Journal, 1, 914.

Hardy, A. V. (1943). In Brucellosis in Man and Animals, edited by I. F. Huddleson, p. 104. Commonwealth Fund, New York.

Hart, F. D., Morgan, A., and Lacey, B. (1951). Brucella abortus endocarditis. British Medical Journal, 1, 1048.

Hassan, A., Erian, M. M., Farid, Z., Hathout, S. D. and Sorensen, K. (1971). Trimethoprimsulphamethoxazole in acute brucellosis. British Medical Journal, 3, 159.

Henderson, R. J. (1973). Brucellosis: the situation in Britain. Health Trends, 5, 10.

Joint FAO/WHO Expert Committee on Brucellosis. Fifth Report, Geneva (1971). WHO Technical Report Series Number 464. World Health Organization, Geneva.
Jones, M. (1950). Subacute bacterial endocarditis of non-streptococcal etiology. A review of the literature in the thirteen-year period 1936-1948 inclusive. American Heart Journal, 40, 106.

Kerr, W. R., McCaughey, W. J., Coghlan, J. D., Payne, D. J. H., Quaife, R. A., Robertson, L., and Farrell, I. D. (1968). Techniques and interpretations in the serological diagnosis of brucellosis in man. Journal of Medical Microbiology, 1 , 181.

Marquis, V. and Haskell, P. (1967). The Cheese Book, p. 28. Published by Leslie Frewin, London, for the Cookery Book Club.

Payne, D. J. H. (1973). Personal communication.

Peery, T. M. and Belter, L. F. (1960). Brucellosis and heart disease II. Fatal brucellosis: A review of the literature and report of new cases. American Journal of Pathology, 36, 673.

Phillips, I., Eykyn, S., and Laker, M. (1972). Outbreak of hospital infection caused by contaminated autoclaved fluids. Lancet, 1, 1258.

Rennie, J. K. and Young, C. J. (1936). Malignant endocarditis due to Brucella abortus. British Medical Journal, 1, 412.

Shafer, R. B. and Hall, W. H. (1970). Bacterial endocarditis following open heart surgery. American Journal of Cardiology, 25, 602.

Vogler, W. R., Dorney, E. R., and Bridges, H. A. (1962). Bacterial endocarditis. A review of 148 cases. American Journal of Medicine, 32, 910.

Requests for reprints to: Dr. Susannah Eykyn, Department of Microbiology, St. Thomas' Hospital, London SE1. 